\title{
A Study of Isomeric Diglycosyl Flavonoids by SORI CID of Fourier Transform Ion Cyclotron Mass Spectrometry in Negative Ion Mode
}

\author{
Cunyu Yan, ${ }^{\text {a,b }}$ Shuying Liu, ${ }^{\mathrm{a}}$ Yihan Zhou, ${ }^{\mathrm{c}}$ Fengrui Song, ${ }^{\mathrm{a}}$ Meng Cui, ${ }^{\mathrm{a}}$ \\ and Zhiqiang $\mathrm{Liu}^{\mathrm{a}}$ \\ ${ }^{a}$ Changchun Center of Mass Spectrometry, Changchun Institute of Applied Chemistry, Chinese Academy of \\ Sciences, Changchun, People's Republic of China \\ ${ }^{\mathrm{b}}$ Graduate School of Chinese Academy of Sciences, Beijing, People's Republic of China \\ ${ }^{\mathrm{c}}$ Institute of Theoretical Chemistry, State Key Laboratory of Theoretical and Computational Chemistry, Jilin \\ University, Changchun, People's Republic of China
}

\begin{abstract}
High-resolution Sustained off resonance irradiation (SORI) CID was employed to distinguish four pairs of isomeric diglycosyl flavonoids in the negative mode using the electrospray ionization Fourier transform ion cyclotron resonance mass spectrometry (ESI FTICR MS). All of these isomers can be distinguished via MS/MS data. For these diglycosyl flavones and flavanones, the deprotonated $\alpha 1 \rightarrow 6$ linkage diglycosyl flavonoids produce fewer fragments than the $\alpha 1 \rightarrow 2$ linkage type compounds and the Retro-Diels-Alder (RDA) reaction in MS/MS only takes place when the aglycone is a flavanone and glycosylated with an $\alpha 1 \rightarrow 2$ intersaccharide linkage disaccharide. The deprotonation sites after collisional activation are discussed according to the high mass accuracy and high-resolution data of tandem spectrometry. Some of these high-resolution SORI CID product ions from $\alpha 1 \rightarrow 2$ linkage diglycosyl flavonoids involve multibond cleavages; the possible mechanism is discussed based on the computer modeling using Gaussian 03 program package at the B3LYP/6-31G level of theory. Unambiguous elementary composition data provides fragmentation information that has not been reported previously. (J Am Soc Mass Spectrom 2007, 18, 2127-2136) @ 2007 American Society for Mass Spectrometry
\end{abstract}

$\mathrm{W}$ ith high mass measurement accuracy and high-resolution, Fourier transform ion cyclotron resonance mass spectrometry (FTICR MS) is at a unique position among all kinds of mass spectrometers. The data of high mass measurement accuracy usually can be used to determine the possible elemental compositions of some organic ions or their fragments based on the exact elemental mass. This can provide blocks of information about the parent ion. High resolution can distinguish adjacent peaks in the mass/charge ratio. Combined with the high mass measurement accuracy of tandem MS data, they provide logical and unambiguous ion fragmentation pathways. Sustained off resonance irradiation (SORI) is a collision induced dissociation technique $[1,2]$ that provides fragment information of target precursor ions.

Flavonoid glycosides, representing a large group of naturally occurring secondary plant metabolites, are widely found in many plants that possess a biosynthetic ability [3, 4]. Many publications demonstrate that flavonoids have numerous wide biological activities [5-7]. Structures of flavonoids have been correlated with their

Address reprint requests to Professor S. Liu, Changchun Center of Mass Spectrometry, Changchun Institute of Applied Chemistry, Chinese Academy of Sciences, Changchun 130022, P. R. China. E-mail: syliu@ciac.jl.cn bioactivities $[8,9]$, so it is crucial to provide authentic molecular structures via a time-saving method, e.g., mass spectrometry. Most of the previous papers have elucidated the structures of flavonoids based on lowresolution mass data, including the differentiation of flavonoid isomers $[10,11]$ and multiglycosyl flavonoid structures [12, 13]. Because most glycosyl flavonoids consist of $\mathrm{C}, \mathrm{H}$, O elements only, sometimes the analysis of the fragmentation pathways and the structures have been inconclusive based on low-resolution data, for example with an ion trap mass spectrometer [14]. March et al. employed high-resolution and exact mass / charge measurements of flavonoids by using Q-TOF mass spectrometry [15]. In 2004, Liu and coworkers employed FTICR MS to verify a proposed neutral losses from the precursor ion of wogonin extracted from the Chinese medicinal herb Scutellaria baicalensis Georgi [16]. All these studies employing high-resolution and high mass methods to analyze known or unknown compounds were successful in providing more detailed fragment assignment.

The purpose of our work is to elucidate the fragmentation pathways of four pairs of isomeric diglycosyl flavonoids based on high mass accuracy and ultrahigh resolution measurements. Charge site location of the 
Table 1. Structures of diglycosyl flavonoids studied

\begin{tabular}{|c|c|c|c|c|c|c|}
\hline Number & Name & {$[\mathrm{M}-\mathrm{H}]^{-}$} & Aglycone & $\mathrm{R}_{1}$ & $\mathrm{R}_{2}$ & $\mathrm{R}_{3}$ \\
\hline a1 & naringin & 579.17193 & & rhamnosyl-( $\alpha 1 \rightarrow 2)$-glucosyl & $\mathrm{H}$ & $\mathrm{OH}$ \\
\hline a2 & narirutin & 579.17193 & & rhamnosyl-( $\alpha 1 \rightarrow 6)$-glucosyl & $\mathrm{H}$ & $\mathrm{OH}$ \\
\hline b1 & neohesperidin & 609.18249 & & rhamnosyl-( $(\alpha 1 \rightarrow 2)$-glucosyl & $\mathrm{OH}$ & $\mathrm{OCH} 3$ \\
\hline b2 & hesperidin & 609.18249 & Flavanone & rhamnosyl-( $(\alpha 1 \rightarrow 6)$-glucosyl & $\mathrm{OH}$ & $\mathrm{OCH} 3$ \\
\hline c1 & rhoifolin & 577.15628 & & rhamnosyl-( $(\alpha 1 \rightarrow 2)$-glucosyl & $\mathrm{H}$ & $\mathrm{OH}$ \\
\hline c2 & isorhoifolin & 577.15628 & & rhamnosyl-( $\alpha 1 \rightarrow 6)$-glucosyl & $\mathrm{H}$ & $\mathrm{OH}$ \\
\hline d1 & neodiosmin & 607.16684 & & rhamnosyl-( $(\alpha 1 \rightarrow 2)$-glucosyl & $\mathrm{OH}$ & $\mathrm{OCH} 3$ \\
\hline d2 & diosmin & 607.16684 & Flavanone & rhamnosyl-( $(\alpha 1 \rightarrow 6)$-glucosyl & $\mathrm{OH}$ & $\mathrm{OCH} 3$ \\
\hline
\end{tabular}

activated diglycosyl flavonoids is also discussed according to the fragment ion information.

\section{Experimental}

\section{Standards and Chemicals}

Acetonitrile was purchased from Fisher (Fair Lawn, NJ) 18.2 $\mathrm{M} \Omega$ ultra purity water was prepared though a Milli-Q preparation system (Millipore, Molsheim, France), and formic acid was ordered from Sigma-Aldrich (St. Louis, MO). All flavonoid standards, narigin (a1, naringenin-7-O-neohesperidoside), neohesperidin (b1, hesperetin-7-O-neohesperidoside), rhoifolin (c1, apigenin 7-O-neohesperidoside), neodiosmin (d1), naritutin (a2, naringenin-7-O-rutinoside), hesperidin (b2, hesperetin-7-O-rutinoside), isorhoifolin (c2, apigenin-7-O- rutinoside), and diosmin (d2) were purchased from Sigma Chemical (St. Louis, MO) and Extrasynthese (Genay, France) and used without further purification. The information of studied diglycosyl flavonoids were listed in Table 1. All the standards were dissolved in acetonitrile/ water $(1: 1, \mathrm{vol} / \mathrm{vol})$ contained $0.1 \%$ formic acid (vol/vol) to make the final concentration of $20 \mathrm{pmol} / \mu \mathrm{L}$ for analysis.

\section{Mass Spectrometry and Computational Studies}

Mass spectra were acquired using the IonSpec ESIFTICR mass spectrometer (IonSpec, Irvine, CA), equipped with a 7.0 T superconductiong magnet (Cryomagnetics, Oak Ridge, TN) and a Z-Spray ESI source (Micromass, Manchester, UK). All of the flavonoid stock solutions were introduced into the FTICR MS by a $100 \mu \mathrm{L}$ gas-tight syringe (Hamilton, Las Vegas, NV) and a Harvard Apparatus syringe pump (Holliston, MA) at a flow rate of $2 \mu \mathrm{L} / \mathrm{min}$ directly. The operating parameters were as follows: probe HV was set to 2500 $\mathrm{V}$, sample cone and extractor cone were set to -30 and $-5 \mathrm{~V}$, respectively; high purity nitrogen was used as desolation gas and cone gas, their initial voltages set to
$0 \mathrm{~V}$ and $0.5 \mathrm{~V}$; the pos/neg ions initial voltage was $5 \mathrm{~V}$; 45 torr nitrogen was used as the collision gas which was introduced into the ICR cell by a pulse valve, the pulse duration was $250 \mathrm{~ms}$. Only the monoisotope precursor ion was selected by an arbitrary chirp sequence, followed by a $800 \mathrm{~ms}$ SORI sequence starting from when collision gas was introduced into the ICR cell. All the flavonoid precursor ions were excited by an offset frequency of $1000 \mathrm{~Hz}$ corresponding to the precursor ions' resonance frequency; the amplitude of excitation frequency was altered from 2.7 to $3.3 \mathrm{~V}$ (peak-to-peak voltage) to control the precursor ions' relative abundance at $20 \%$ to $40 \%$ in their MS/MS spectra. Quantum chemistry calculations of four pairs of deprotonated isomeric diglycosyl flavonoids were performed on SGI O3800 workstation using Gaussian 03 program package [17]. All of the geometries were optimized at the B3LYP/6-31G level of theory.

\section{Results and Discussion}

\section{Nomenclature}

We combined two nomenclature systems for product ions in this paper. For product ions that contain the intact A- and B-ring of the flavonoid aglycone skeleton, the nomenclature system suggested by Claeys and coworkers [18] was used in which ions were labeled as ${ }^{i, j} A$ and ${ }^{i, j} B$ with superscripts $i$ and $j$ indicating the position of bonds broken in the C-ring. For product ions related to the cleavage of the carbohydrate part in the flavonoids, we adopted the nomenclature according to Domon and Costello [19], where ions retaining the charge at the reducing terminus were labeled $Y_{j}, Z_{j}$, (glycosidic cleavages) and ${ }^{k, l} X_{j}$ (cross-ring cleavages) with superscripts $k$ and 1 indicating the cleavage site of the carbohydrate rings. An integral nomenclature system is illustrated for naringin in Scheme 1. 


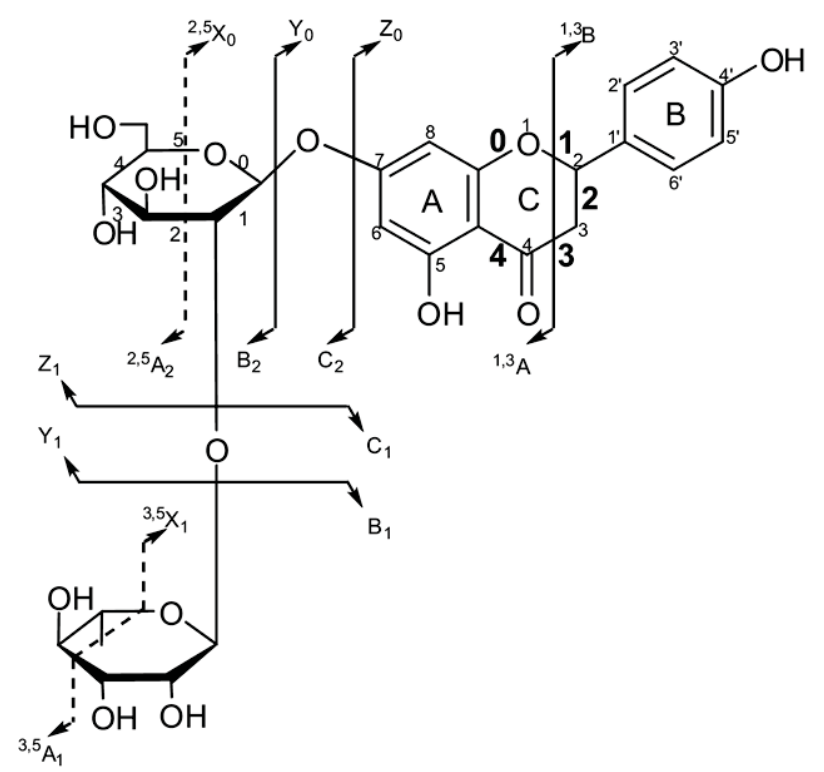

Scheme 1. Nomenclature adopted for diglycosyl flavonoids (illustrated on naringin).

\section{Internal Calibration Strategy for Tandem Mass Spectrometry (MS/MS) of Diglycosyl Flavonoids}

To gain an even higher mass measurement accuracy compared with routine external calibration procedure for product ions, a two-step internal calibration strategy without dopants was applied: first, only an unambiguous deprotonated molecule was selected to calibrate the mass spectrum. Second, the $Y_{0}^{-}$fragment ion from glycosidic cleavage in both $\alpha 1 \rightarrow 6$ and $\alpha 1 \rightarrow 2$ linkage of diglycosyl flavonoids was added to the calibration list. This di-peak calibration strategy improves mass mea- surement accuracy to provide a more reliable elemental composition of other fragment ions. After these two steps, a relative mass measurement error less than 1.00 ppm could be obtained.

\section{Negative Charge Site Location of Deprotonated Flavonoids}

Charge site determination of ionized analyte is an important topic of mass spectrometry. An in-depth understanding of the charge sites is helpful for elucidating the molecular structures and probing the physical properties of precursor ions. It was found that in some cases the location of the proton is mobile during activation, which results in the formation of a complex array of fragment ions [20, 21]. Charge site determination will lead to a detailed understanding of product ion formation and fragmentation pathways. However, the charge site of activated precursor ion is uncertain in most cases, especially for a deprotonated negative precursor ion.

In our study, we attempt to elucidate the deprotonation position of energized precursor ions of diglycosyl flavonoids formed by negative ESI mass spectrometry. The tandem spectra data of $\alpha 1 \rightarrow 2$ linkage diglycosyl flavonoids are shown in Tables 2, 3, 4, and 5. Naringin was selected as a model compound according to its abundant product ions. The proton abstraction position of collisionally activated flavonoids was deduced based on product ions. Elementary composition calculations of product ions were based on the low mean error MS/MS results.

In Table 2, the product ion $\mathrm{Y}_{0}^{-}$of flavonoids indicates the deprotonation charge site located on the aglycone.

Table 2. Fragments of high resolution SORI CID for naringin in Figure 1, a1.

\begin{tabular}{|c|c|c|c|c|c|}
\hline Fragments & Elem. comp. & Measured $\mathrm{m} / \mathrm{z}$ & Calculated $\mathrm{m} / \mathrm{z}$ & Relative intensity & Error (ppm) \\
\hline $\mathrm{Y}_{0}{ }^{1,3} \mathrm{~A}^{-}$ & $\mathrm{C}_{7} \mathrm{H}_{3} \mathrm{O}_{4}^{-}$ & 151.0037 & 151.0037 & 0.737 & 0.00 \\
\hline $\mathrm{C}_{1}^{-}$ & $\mathrm{C}_{6} \mathrm{H}_{11} \mathrm{O}_{5}^{-}$ & 163.0612 & 163.0612 & 4.075 & 0.00 \\
\hline${ }^{0,2} \mathrm{X}_{1}{ }^{0,2} \mathrm{X}_{0}{ }^{1,3} \mathrm{~A}^{-}$ & $\mathrm{C}_{11} \mathrm{H}_{7} \mathrm{O}_{6}^{-}$ & 235.0249 & 235.0248 & 5.397 & 0.43 \\
\hline${ }^{2,5} \mathrm{X}_{1}{ }^{2,5} \mathrm{X}_{0}{ }^{1,3} \mathrm{~A}^{-}$ & $\mathrm{C}_{11} \mathrm{H}_{11} \mathrm{O}_{8}^{-}$ & 271.0461 & 271.0459 & 2.532 & 0.74 \\
\hline $\mathrm{Y}_{0}^{-}$ & $\mathrm{C}_{15} \mathrm{H}_{11} \mathrm{O}_{5}^{-}$ & 271.0612 & 271.0612 & 44.671 & 1 \\
\hline$\left[0,2 X_{0} Z_{1}-H_{2}\right]^{-}$ & $\mathrm{C}_{17} \mathrm{H}_{11} \mathrm{O}_{5}^{-}$ & 295.0613 & 295.0612 & 1.961 & 0.34 \\
\hline $0,2 X_{0} Y_{1}-$ & $\mathrm{C}_{17} \mathrm{H}_{13} \mathrm{O}_{6}^{-}$ & 313.0719 & 313.0718 & 21.648 & 0.32 \\
\hline$\left[{ }^{0,2} \mathrm{X}_{1}{ }^{0,2} \mathrm{X}_{0}-\mathrm{H}_{2} \mathrm{O}\right]^{-}$ & $\mathrm{C}_{19} \mathrm{H}_{13} \mathrm{O}_{6}^{-}$ & 337.0719 & 337.0718 & 1.731 & 0.30 \\
\hline${ }^{1,5} X_{1}{ }^{0,2} X_{0}$ & $\mathrm{C}_{18} \mathrm{H}_{15} \mathrm{O}_{7}^{-}$ & 343.0824 & 343.0823 & 1.913 & 0.29 \\
\hline${ }^{0,2} X_{1}^{0,2} X_{0}^{-}$ & $\mathrm{C}_{19} \mathrm{H}_{15} \mathrm{O}_{7}^{-}$ & 355.0825 & 355.0823 & 2.414 & 0.56 \\
\hline${ }^{1,3} X_{0} \quad$ or ${ }^{2,5} X_{0} Y_{1}$ & $\mathrm{C}_{19} \mathrm{H}_{17} \mathrm{O}_{8}$ & 373.0929 & 373.0929 & 13.175 & 0.00 \\
\hline$\left[{ }^{2,4} \mathrm{X}_{1}{ }^{0,2} \mathrm{X}_{0} ?-\mathrm{H}_{2}\right]^{-}$ & $\mathrm{C}_{21} \mathrm{H}_{17} \mathrm{O}_{8}^{-}$ & 397.0930 & 397.0929 & 8.500 & 0.25 \\
\hline${ }^{2,4} X_{1}{ }^{0,2} X_{0}$ & $\mathrm{C}_{21} \mathrm{H}_{19} \mathrm{O}_{8}^{-}$ & 399.1086 & 399.1085 & 1.571 & 0.25 \\
\hline$\left[\mathrm{Z}_{1}-\mathrm{H}_{2}\right]^{-}$ & $\mathrm{C}_{21} \mathrm{H}_{19} \mathrm{O}_{9}^{-}$ & 415.1036 & 415.1035 & 0.962 & 0.24 \\
\hline $\mathrm{Z}_{1}^{-}$ & $\mathrm{C}_{21} \mathrm{H}_{21} \mathrm{O}_{9}^{-}$ & 417.1191 & 417.1191 & 7.006 & 0.00 \\
\hline $\mathrm{Y}_{1}^{-}$ & $\mathrm{C}_{21} \mathrm{H}_{21} \mathrm{O}_{10}{ }^{-}$ & 433.1145 & 433.1140 & 0.691 & 1.15 \\
\hline$\left[{ }^{1,3} \mathrm{~A}-\mathrm{H}_{2} \mathrm{O}\right]^{-}$ & $\mathrm{C}_{19} \mathrm{H}_{21} \mathrm{O}_{12}^{-}$ & 441.1041 & 441.1039 & 2.145 & 0.45 \\
\hline${ }^{1,3} \mathrm{~A}^{-}$ & $\mathrm{C}_{19} \mathrm{H}_{23} \mathrm{O}_{13}-$ & 459.1148 & 459.1144 & 100.000 & 0.87 \\
\hline${ }^{0,2} \mathrm{X}_{0}^{-}$ & $\mathrm{C}_{23} \mathrm{H}_{23} \mathrm{O}_{10}^{-}$ & 459.1288 & 459.1297 & 10.910 & -1.96 \\
\hline $1,2 \mathrm{~A}^{-}$ & $\mathrm{C}_{20} \mathrm{H}_{25} \mathrm{O}_{13}^{-}$ & 473.1304 & 473.1301 & 4.475 & 0.63 \\
\hline$[\mathrm{M}-\mathrm{H}]^{-}$ & $\mathrm{C}_{27} \mathrm{H}_{31} \mathrm{O}_{14}^{-}$ & 579.1719 & 579.1719 & 24.141 & 1 \\
\hline & & & \multicolumn{2}{|c|}{ Mean value: } & 0.29 \\
\hline
\end{tabular}


Table 3. Fragments of high resolution SORI CID for neohesperidin in Figure 2, b1

\begin{tabular}{|c|c|c|c|c|c|}
\hline Fragments & Elem. comp. & Measured $\mathrm{m} / \mathrm{z}$ & Calculated $\mathrm{m} / \mathrm{z}$ & Relative intensity & Error (ppm) \\
\hline $\mathrm{C}_{1}^{-}$ & $\mathrm{C}_{6} \mathrm{H}_{11} \mathrm{O}_{5}^{-}$ & 163.0613 & 163.0612 & 6.327 & 0.61 \\
\hline $\mathrm{Y}_{0}^{-}$ & $\mathrm{C}_{16} \mathrm{H}_{13} \mathrm{O}_{6}^{-}$ & 301.0718 & 301.0718 & 100.000 & I \\
\hline$\left[{ }^{0,2} \mathrm{X}_{0} \mathrm{Y}_{1}-\mathrm{CO}\right]^{-}$ & $\mathrm{C}_{17} \mathrm{H}_{15} \mathrm{O}_{6}^{-}$ & 315.0876 & 315.0874 & 2.545 & 0.63 \\
\hline$\left[{ }^{0,2} \mathrm{X}_{0} \mathrm{Z}_{1}-\mathrm{H}_{2}\right]^{-}$ & $\mathrm{C}_{18} \mathrm{H}_{13} \mathrm{O}_{6}^{-}$ & 325.0720 & 325.0718 & 5.427 & 0.62 \\
\hline${ }^{0,2} \mathrm{X}_{0} \mathrm{Y}_{1}-$ & $\mathrm{C}_{18} \mathrm{H}_{15} \mathrm{O}_{7}^{-}$ & 343.0825 & 343.0823 & 25.281 & 0.58 \\
\hline${ }^{0,3} X_{0} Z_{1}-$ & $\mathrm{C}_{19} \mathrm{H}_{15} \mathrm{O}_{7}^{-}$ & 355.0827 & 355.0823 & 1.699 & 1.13 \\
\hline$\left[{ }^{0,2} \mathrm{X}_{1}{ }^{0,2} \mathrm{X}_{0}-\mathrm{H}_{2} \mathrm{O}\right]^{-}$ & $\mathrm{C}_{20} \mathrm{H}_{15} \mathrm{O}_{7}^{-}$ & 367.0826 & 367.0823 & 4.477 & 0.82 \\
\hline${ }^{1,5} X_{1}^{0,2} X_{0}^{-}$ & $\mathrm{C}_{19} \mathrm{H}_{17} \mathrm{O}_{8}^{-}$ & 373.0932 & 373.0929 & 2.082 & 0.80 \\
\hline${ }^{0,2} \mathrm{X}_{1}^{0,2} \mathrm{X}_{0}^{-}$ & $\mathrm{C}_{20} \mathrm{H}_{17} \mathrm{O}_{8}^{-}$ & 385.0932 & 385.0929 & 4.656 & 0.78 \\
\hline${ }^{1,3} \mathrm{X}_{0}{ }^{-}$or ${ }^{2,5} \mathrm{X}_{0} \mathrm{Y}_{1}{ }^{-}$ & $\mathrm{C}_{20} \mathrm{H}_{19} \mathrm{O}_{9}^{-}$ & 403.1038 & 403.1035 & 3.559 & 0.74 \\
\hline$\left[{ }^{2,4} \mathrm{X}_{1}{ }^{0,2} \mathrm{X}_{0}-\mathrm{H}_{2}\right]^{-}$ & $\mathrm{C}_{22} \mathrm{H}_{19} \mathrm{O}_{9}^{-}$ & 427.1038 & 427.1035 & 1.282 & 0.70 \\
\hline${ }^{2,4} \mathrm{X}_{1}{ }^{0,2} \mathrm{X}_{0}$ & $\mathrm{C}_{22} \mathrm{H}_{21} \mathrm{O}_{9}^{-}$ & 429.1194 & 429.1191 & 3.107 & 0.70 \\
\hline$\left[\mathrm{Z}_{1}-\mathrm{H}_{2}\right]^{-}$ & $\mathrm{C}_{22} \mathrm{H}_{21} \mathrm{O}_{10}-$ & 445.1144 & 445.1140 & 1.187 & 0.90 \\
\hline $\mathrm{Z}_{1}^{-}$ & $\mathrm{C}_{22} \mathrm{H}_{23} \mathrm{O}_{10}{ }^{-}$ & 447.1300 & 447.1297 & 4.774 & 0.67 \\
\hline $\mathrm{Y}_{1}{ }^{-}$ & $\mathrm{C}_{22} \mathrm{H}_{23} \mathrm{O}_{11}^{-}$ & 463.1248 & 463.1246 & 1.780 & 0.43 \\
\hline${ }^{0,2} \mathrm{X}_{0}^{-}$ & $\mathrm{C}_{24} \mathrm{H}_{25} \mathrm{O}_{11}^{-}$ & 489.1405 & 489.1402 & 9.413 & 0.61 \\
\hline$[\mathrm{M}-\mathrm{H}]^{-}$ & $\mathrm{C}_{28} \mathrm{H}_{33} \mathrm{O}_{15}{ }^{-}$ & 609.1825 & 609.1825 & 15.159 & I \\
\hline & & & \multicolumn{2}{|c|}{ Mean value: } & 0.73 \\
\hline
\end{tabular}

No RDA fragmentation.

${ }^{1,3} \mathrm{~A}^{-}\left(\mathrm{m} / \mathrm{z}\right.$ 271.0612) and $\mathrm{Y}_{0}{ }^{1,3} \mathrm{~A}^{-}(\mathrm{m} / \mathrm{z}$ 151.0037) of naringin indicate that the deprotonated group is on the 5-OH on the A-ring. The 4-carbonyl and 1-O- of C-ring make the phenol hydroxyl on the A-ring considerably more acidic than the hydroxyls of the disaccharides. The 4-carbonyl of the C-ring is at the $\alpha$ position of aromatic A-ring, which possesses the keto-enol property and the 4-OH of its enol tautomer as shown in Scheme 2 (M: enol structure) is also an acidic group, however, the phenol hydroxyl is a stronger acid than the hydroxyl of enol form, so the charge site of flavonoids is located on the $5-\mathrm{OH}$. The resonance structure of deprotonated flavonoid is shown in the Scheme 2 (illustrated for naringin). The 4-OH of the enol form shares its proton with deprotonated $5-\mathrm{O}^{-}$to form a stable six-member ring. Multiresonance structures stabilize the proton abstraction structure. The $\mathrm{C}_{1}^{-}$ion of naringin and neohesperidin is produced when the negative charge site is located on the sugar moiety. The lower relative abundance and fewer correlative fragments indicate that this charge site location is not the dominant proton abstraction pathway. Because the charge of an ion is mobile, the possibility of charge site strongly depends on the environment around the charge of an ion. In ICR cell, the product ions ${ }^{1,3} \mathrm{~A}^{-}(\mathrm{m} / \mathrm{z}$ 459.1148), $\mathrm{Y}_{0}{ }^{1,3} \mathrm{~A}^{-}$( $m / z$ 151.0037), ${ }^{1,2} \mathrm{~A}^{-}$( $m / z$ 473.1304),
${ }^{0,2} \boldsymbol{X}_{1}{ }^{0,2} \boldsymbol{X}_{0}{ }^{1,3} \mathrm{~A}^{-}(\mathrm{m} / \mathrm{z} 235.0249)$ and ${ }^{2,5} \mathrm{X}_{1}{ }^{2,5} \mathrm{X}_{0}{ }^{1,3} \mathrm{~A}^{-}(\mathrm{m} / \mathrm{z}$ 271.0461) from deprotonated flavonoids (in Table 2) indicate the higher possibility of charge site located on $5-\mathrm{OH}$ rather than other positions. To gain more information on the deprotonation position, the $\mathrm{MS}^{3}$ spectrum of $\mathrm{Y}_{0}^{-}$(naringin) was given in Figure 1. The base peak $\mathrm{Y}_{0}^{1,3} \mathrm{~A}^{-}(\mathrm{m} / \mathrm{z}$ 151.0034) and other product ions $\left[\mathrm{Y}_{0}-\mathrm{B}\right]^{-}(\mathrm{m} / \mathrm{z} 177.0191), \mathrm{Y}_{0}{ }^{1,2} \mathrm{~A}^{-}(\mathrm{m} / \mathrm{z} 165.0191), \mathrm{Y}_{0}{ }^{1,4} \mathrm{~A}^{-}$ $(\mathrm{m} / \mathrm{z}$ 125.0241) show that the most likely charge site is to be located on A-ring. The charged B-ring related fragment, ${ }^{1,3} \mathbf{B}^{-}(m / z 119.04,898)$, is presented with a very low relative intensity (R. I. $<3 \%$ ). These data further confirm that the charge site should be located on $5-\mathrm{OH}$ after collisional activation with a higher possibility. The 7-OH of aglycone is glycosylated for a deprotonated diglycosyl flavonoid. Other flavonoids were studied systemically, which also provided the same results. It seems that the deduced deprotonation position based on tandem mass spectrometry is not consistent with literature $[22,23]$, which indicates that proton abstraction happened on the $4^{\prime}-\mathrm{OH}$ based on the $-\mathrm{OH}$ acidity calculation via ab initio. We consider that different results come from different research methods. Zhang assigned the most acidic $-\mathrm{OH}$ on aglycone for the ionization position when the proton abstraction reaction took place [23], the ionized molecule was on its

Table 4. Fragments of high resolution SORI CID for rhoifolin in Figure 2, c1.

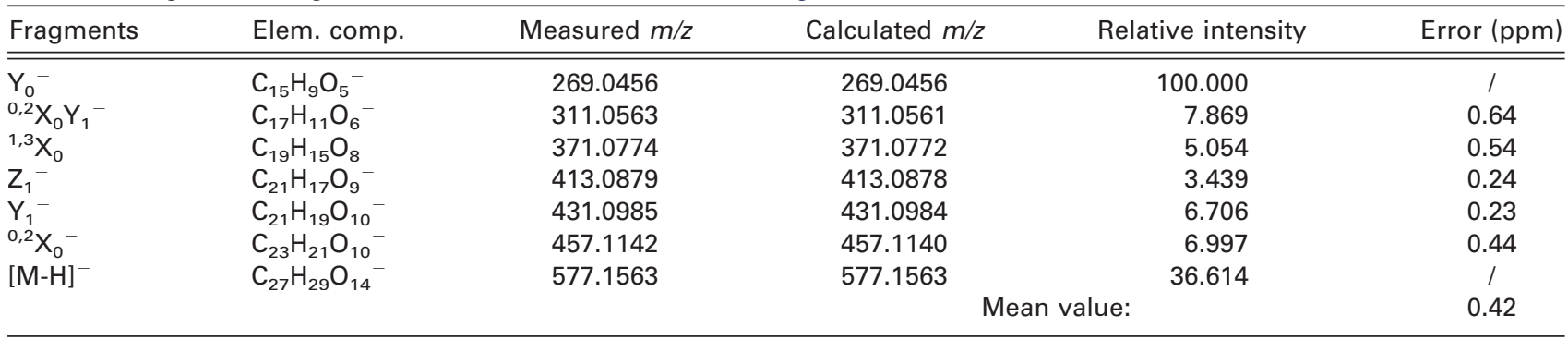


Table 5. Fragments of high resolution SORI CID for neodiosmin in Figure 2, d1.

\begin{tabular}{llcccc}
\hline Fragments & Elem. comp. & Measured $m / z$ & Calculated $m / z$ & Relative intensity & Error (ppm) \\
\hline \hline$\left[\mathrm{Y}_{0^{-}} \cdot \mathrm{CH}_{3}\right]^{-}$ & $\mathrm{C}_{15} \mathrm{H}_{8} \mathrm{O}_{6}^{-}$ & 284.0326 & 284.0327 & 3.996 & 0.35 \\
$\mathrm{Y}_{0}^{-}$ & $\mathrm{C}_{16} \mathrm{H}_{11} \mathrm{O}_{6}^{-}$ & 299.0561 & 299.0561 & 18.120 & $/$ \\
{$[\mathrm{M}-\mathrm{H}]^{-}$} & $\mathrm{C}_{28} \mathrm{H}_{31} \mathrm{O}_{15}$ & 607.1668 & 607.1668 & 100.000 & $/$ \\
& & & & Mean value: & 0.35 \\
\hline
\end{tabular}

ground state for the soft ionization condition of ESI. However, the deprotonation position determination based on the product ions of mass spectrometry provides direct evidence of a charge site location for a precursor ion on its excited-state after accumulating enough energy by the SORI CID process. There maybe a charge-transfer process involved for an ionized molecule from ground state to excited-state. Based on the above discussion, the charge site of a collisionally activated deprotonated diglycosyl flavonoid ion in the ICR cell favors the $5-\mathrm{OH}$ on the aglycone. Charge site determination provides us with a chance to understand the dissociation processes in SORI-CID mass spectrometry more deeply.

\section{Differentiation of Flavonoid Glycosides Isomers}

Each pair of isomeric flavonoids has the same aglycone shown in Table 1. The only difference between a pair of isomeric flavonoid is the linkage type of disaccharide moiety at the 7-OR ${ }_{1}$ of the aglycone's A-ring. Compounds a1, b1, c1, and d1 have the same rhamnosyl-

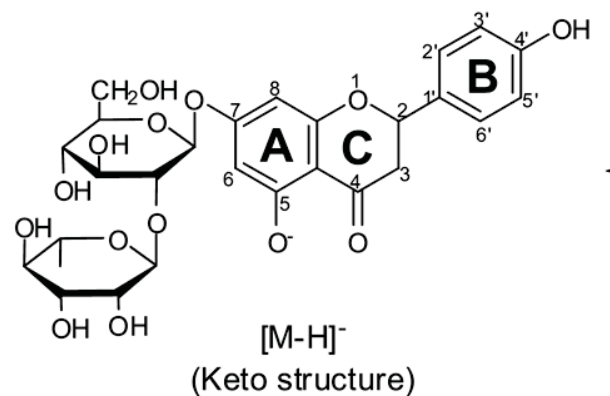<smiles>OC1=CC(c2ccc(O)cc2)Oc2cc(O)cc(O)c21</smiles>

(Keto structure)

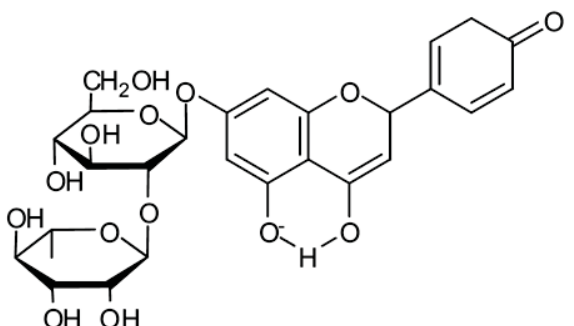

$[\mathrm{M}-\mathrm{H}]^{-}$

resonance structure of cyclohexadiene-one form

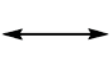

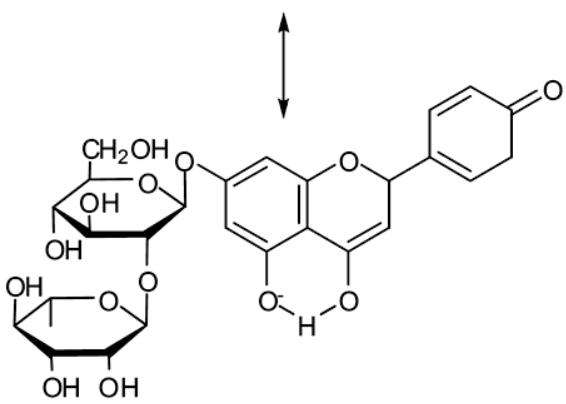

$[\mathrm{M}-\mathrm{H}]^{-}$

resonance structure of cyclohexadiene-one form

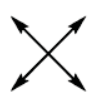

$[\mathrm{M}-\mathrm{H}]^{-}$

resonance structure of phenol form

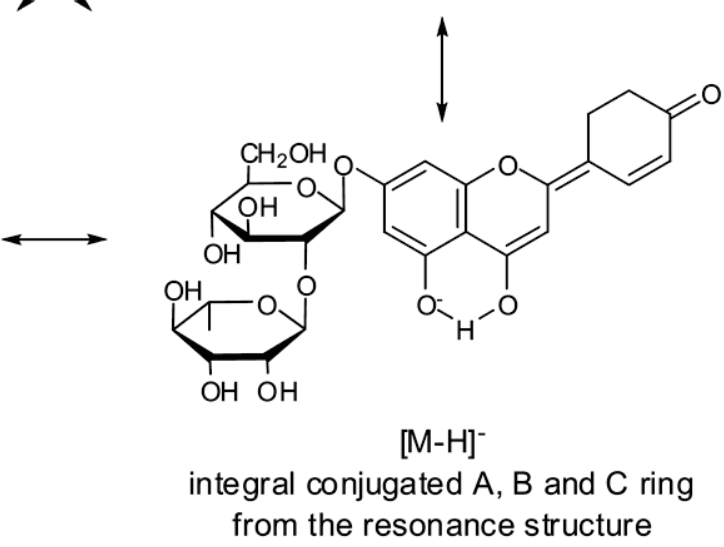

Scheme 2. The schematic resonance structures of deprotonated naringin. 


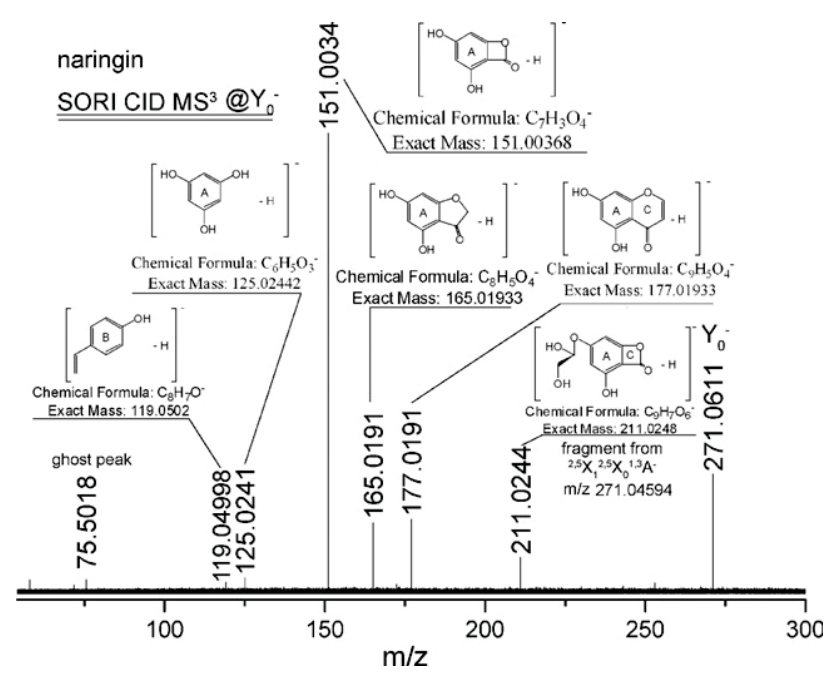

Figure 1. SORI CID tandem mass spectra of $\mathrm{Y}_{0}^{-}\left([\mathrm{M}-\mathrm{H}]^{-} \rightarrow \mathrm{Y}_{0}^{-}\right.$ $\left({ }^{2,5} \mathrm{X}_{1}^{2,5} \mathrm{X}_{0}^{1,3} \mathrm{~A}^{-}\right) \rightarrow$.

$(\alpha 1 \rightarrow 2)$-glucose disaccharide moiety, and a2, b2, c2, and $\mathrm{d} 2$ have the same rhamnosyl- $(\alpha 1 \rightarrow 6)$-glucose disaccharide moiety. Figure 2 shows the SORI CID MS/MS fragments of the four pairs of isomeric diglycosyl flavonoids. The mean value of relative error is controlled within $1.00 \mathrm{ppm}$ when tandem mass spectra are calibrated using the above two-step internal calibration strategy. Of note, different SORI CID results are exhibited in Figure 1; the precursor ion with the rhamnosyl$(\alpha 1 \rightarrow 2)$-glucose disaccharide moiety is more fragile than the $(\alpha 1 \rightarrow 6)$ isomeric molecule under the same SORI CID condition. The abundant fragments are listed in Tables $2-5$. The fragments of $\alpha 1 \rightarrow 2$ isomer provide more structure information of the precursor ions. The fragment ions $\mathrm{Y}_{0}^{-}$and $\mathrm{Y}_{1}^{-}$confirm that the two-glycoside moieties form an interglycosidic linkage, and the cross ring cleavage ion of ${ }^{0,2} \mathrm{X}_{0}^{-}\left([\mathrm{M}-\mathrm{H}]^{-}-90\right)$ indicates $\alpha 1 \rightarrow 2$ inter linkage. However, the deprotonated Compound d1 (neodiosmin) only produces simple tandem mass spectra, which is related to its rigid flavone aglycone and the electron-rich substitutes $-\mathrm{OCH}_{3}$ on the B-ring. Cuyckens et al. had easily distinguished these two linkage types of flavonoids by ion trap mass spectrometry under negative ion mode [11]. The reproducible results make the isomeric flavonoid differentiation more feasible. The deprotonated flavonoid that substitutes its 7-OH of the A-ring with a rhamnosyl$(\alpha 1 \rightarrow 2)$-glucosyl produces more fragment ions that could be related to the hydroxyl group closest to the acetal linkage between the aglycone and the sugar part [24]. MD simulations were applied to the isomeric flavonoids to explain the different fragmentation behaviors of the $\alpha 1 \rightarrow 2$ and the $\alpha 1 \rightarrow 6$ linkage compounds. The deprotonation position was assigned to the $5-\mathrm{OH}$ on the A-ring based on the tandem mass spectrometry data. It is noteworthy that assigning different deprotonation sites will result in totally different MD simulation conformations; Zhang et al. reported another cal- culated conformations for the deprotonated flavonoids [23]. Figure 3 shows the deprotonated hesperidin (b2) and neohesperidin (b1) computer modeling structures in our research system. The $\alpha 1 \rightarrow 6$ linkage disaccharide moiety is more flexible than the $\alpha 1 \rightarrow 2$ linkage types for the -O- $\mathrm{CH}_{2}$-interglycosidic linkage, which leads to form a strong intramolecular hydrogen bond between the deprotonated $5-\mathrm{O}^{-}$on the A-ring and the $4-\mathrm{OH}$ at the rhamnosyl. The distance between $\mathrm{H}$ at $4-\mathrm{OH}$ and $\mathrm{O}$ at 5-O is $1.6149 \AA$, which is even shorter than those in the $\mathrm{HF}$ and $\mathrm{H}_{2} \mathrm{O}$ hydrogen bond system. This result means that the intramolecular hydrogen bond between disaccharide part and the aglycone of $\alpha 1 \rightarrow 6$ linkage flavonoids reduces the possibility of cross ring cleavage both on the sugar part and on the aglycone part. It results in producing fewer fragments compared with the $\alpha 1 \rightarrow 2$ linkage flavonoids. The SORI burst amplitude applied to the $\alpha 1 \rightarrow 2$ linkage flavonoids was $3.4 \mathrm{~V}$, which was much higher than $2.1 \mathrm{~V}$ of the $\alpha 1 \rightarrow 6$ linkage flavonoids. It indicates that the multibond cleavage needs more energy to dissociate to a similar level compared with their counterparts. Flavonoid a2, c2, and $\mathrm{d} 2$ with the $\alpha 1 \rightarrow 6$ linkage disaccharide moiety also form strong intramolecular hydrogen bonds such as hesperidin, and the results are not listed here.

\section{The RDA Fragmentation}

RDA fragmentation is a common dissociation pathway in the mass spectrum of flavone in the positive ion mode [18]. From Figure 2 and the product ions assignment (see Table 2-Table 5), the only RDA fragment of ${ }^{1,3} \mathrm{~A}^{-}$was found in the MS/MS spectra of naringin (see Figure 1, a1. $m / z$ 459.1148), there were no other RDA fragments present in the tandem mass spectra. Cuyckens et al. assigned the base peak $\mathrm{m} / \mathrm{z} 459$ of naringin (a1) to ${ }^{0,2} \boldsymbol{X}_{0}^{-}(m / z 459.1288)$, and assigned the $m / z 459$ of narirutin (a2), which was not found in our experiment, to the RDA fragmentation on the C-ring of the aglycone involving cleavages at bond 1 and 3 [11]. In fact the fragment ${ }^{0,2} \mathrm{X}_{0}^{-}$does exist in the tandem spectra of naringin with only $10.91 \%$ relative intensity shown in the Figure 4 . The dominant fragment is ${ }^{1,3} \mathrm{~A}^{-}$. The $\Delta \mathrm{m}$ between ${ }^{0,2} \mathrm{X}_{0}^{-}$and ${ }^{1,3} \mathrm{~A}^{-}$is only about $0.01526 \mathrm{u}$ based on the calculated $\mathrm{m} / \mathrm{z}$ values. These two considerable adjacent peaks cannot be distinguished by a low-resolution mass spectrometer. High mass accuracy tandem MS data of naringin (showed in Figure 1, a1) indicate that the base peak is ${ }^{1,3} \mathrm{~A}^{-}(\mathrm{m} / \mathrm{z}$ 459.1148). The data allow only one possible elementary composition (hits) for each fragment when $\Delta \mathrm{m}$ window is set to 0.001 . So it is obvious that the fragment $\mathrm{m} / \mathrm{z} 459$ of narirutin (a2) needed to be tested with a high-resolution instrument. Although neohesperidin (b1) has the same aglycone skeleton as naringin (a1), no RDA product ion is shown in the tandem spectra of neohesperidin (see spectra b1 in Figure 2) under the same SORI CID experiment condition as naringin (a1). This indicates that the substituents on the B-ring may affect the stabilization of 

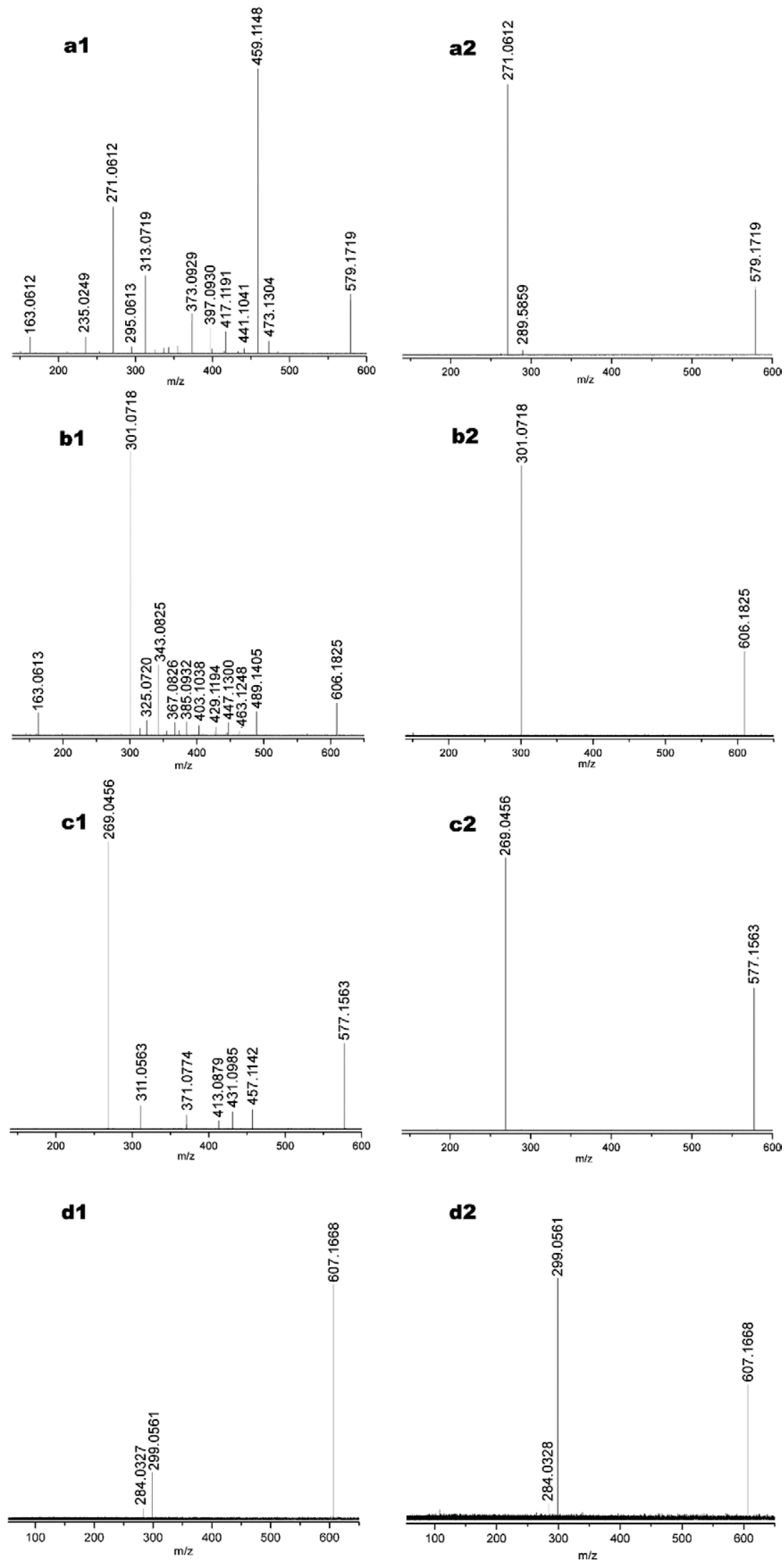

Figure 2. High-resolution SORI CID spectra on $[\mathrm{M}-\mathrm{H}]^{-}$: (a1) naringin, (a2) narirutin, (b1) neohesperidin, (b2) hesperidin, (c1) rhoifolin, (c2) isorhoifolin, (d1) neodiosmin, (d2) diosmin. 

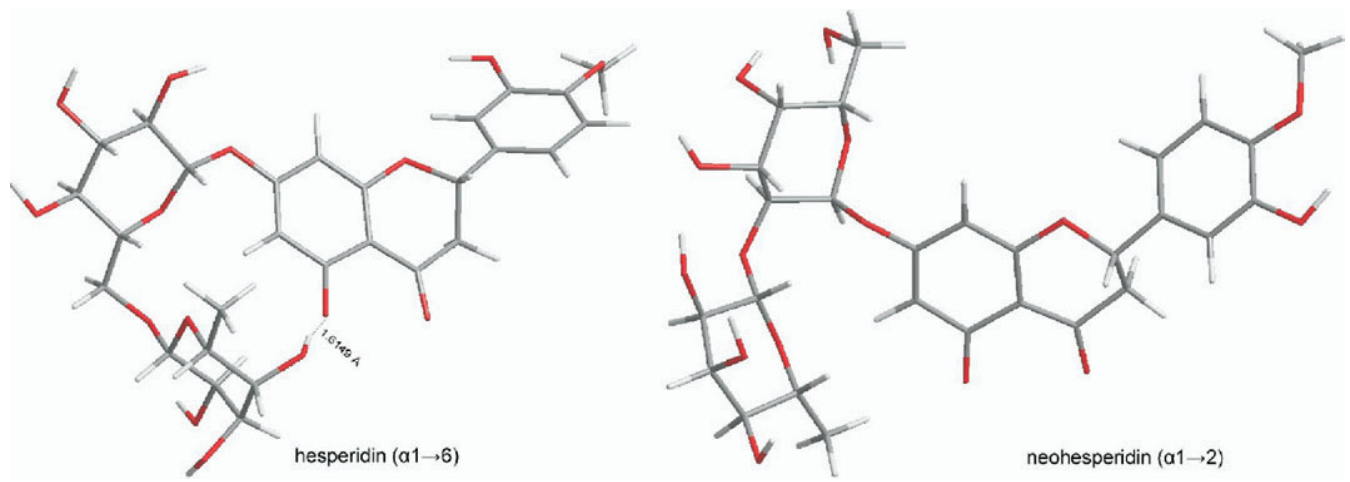

Figure 3. Computer modeling structures of deprotonated hesperidin and neohesperidin.

C-ring. According to synthesis chemistry theory, the product ion ${ }^{1,3} \mathrm{~A}^{-}$is considered as a diene, and the ${ }^{1,3} \mathrm{~B}$ is taken for a dienophile, as two electron-rich groups on the B-ring (the $3^{\prime}-\mathrm{OH}$ and $4^{\prime}-\mathrm{OCH}_{3}$ ) affect the RDA dissociation activity remarkably. RDA fragmentation will not occur when aglycone is a flavone. The doublebond between C (2) and C (3) of the C-ring of the flavone makes aglycone plane more stable than flavonoids with a flavanone skeleton, which forms an integrated rigid $\pi$ conjugated plane with $\mathrm{A}-, \mathrm{B}-$, and C-ring such as rhoifolin (c1) and neodiosmin (d1). Another interesting result is that the entire $\alpha 1 \rightarrow 6$ linkage diglycosyl flavonoids do not experience the RDA process completely under our experimental condition by using SORI CID technique. The rhamnosyl is considered as an integrated electron-releasing group, which donates more electron cloud to the aglycone skeleton when linked to the $2-\mathrm{OH}$ of glucosyl than linked to the 6-OH. The electron-rich isomeric linkage pattern stabilizes the aglycone and reduces the chance of the RDA dissociation process. It can be concluded

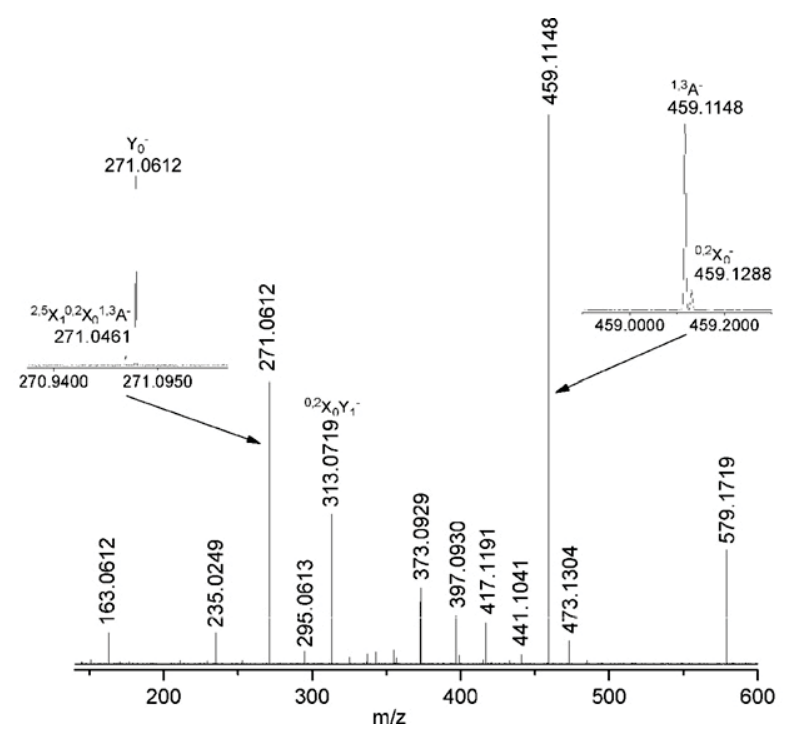

Figure 4. Magnification of Figure 1. a1. High mass accuracy and resolution SORI CID on $\mathrm{m} / \mathrm{z} 271.0612\left(\mathrm{Y}_{0}^{-}\right)$and $\mathrm{m} / \mathrm{z} 459.1148$ $\left({ }^{1,3} \mathrm{~A}^{-}\right)$. that, for these diglycosyl flavone and flavanone, the RDA fragmentation only takes place when the aglycone is flavanone and the aglycone is glycosylated with a diglycosyl of $\alpha 1 \rightarrow 2$ intersaccharide linkage under the negative FTICR SORI CID MS mode.

\section{SORI CID Fragmentation Pathways and MS/MS Spectra of $\alpha 1 \rightarrow 2$ Linkage Diglycosyl Flavonoids}

Single product ion peak in the low-resolution mass spectra could reveal more fragment ions with FTICR MS. The resolution over all fragment ions is from 70,000 to 220,000 in our work, which resolves some much-closed adjacent peaks. For Compound naringin, besides ${ }^{0,2} \mathrm{X}_{0}^{-}$and ${ }^{1,3} \mathrm{~A}^{-}$, we also observed adjacent fragment ions of ${ }^{2,5} \mathrm{X}_{1}{ }^{2,5} \mathrm{X}_{0}{ }^{1,3} \mathrm{~A}^{-}(\mathrm{m} / \mathrm{z} 271.0461)$ and $Y_{0}^{-}(\mathrm{m} / \mathrm{z}$ 271.0612). The product ion $\mathrm{m} / \mathrm{z} 313$ provided by low-resolution mass spectrometers cannot give unambiguous fragmentation pathways information in this case. In fact, this product ion came from the ${ }^{0,2} \mathrm{X}_{0} \mathrm{Y}_{1}^{-}(\mathrm{m} / \mathrm{z} 313.0718)$, not from the $\mathrm{Y}_{1}{ }^{1,3} \mathrm{~A}^{-}$ $(\mathrm{m} / \mathrm{z}$ 313.0565). All fragments information is shown in Table 2 (other $\alpha 1 \rightarrow 2$ linkage isomeric flavonoids product ions are listed from Tables 3-5). Scheme 3 illustrates the possible fragmentation pathways for Compound naringin (a1). The results indicate that the dissociation processes of the precursor ion which took place in the ICR cell with low heating SORI are much more complicated, and can provide us with more valuable data on molecular structural elucidation.

An interesting phenomenon is that many fragment ions of the $1 \rightarrow 2$ linkage diglycosyl flavonoids involves multibond cleavage processes such as the ${ }^{2,5} \mathrm{X}_{1}{ }^{2,5} \mathrm{X}_{0}{ }^{1,3} \mathrm{~A}^{-}$, and the ${ }^{0,2} \mathrm{X}_{1}{ }^{0,2} \mathrm{X}_{0}^{-}$. This phenomenon was also found in the work of Es-Safi et al., but the author did not mention these multibond cleavage processes [24]. These processes usually include RDA cleavages on the aglycone part and cross-ring cleavages on the disaccharide part. Concerted processes may be involved during multibond cleavage, which will form a dissociation transition state of new bond generations and old bond cleavages. The released 

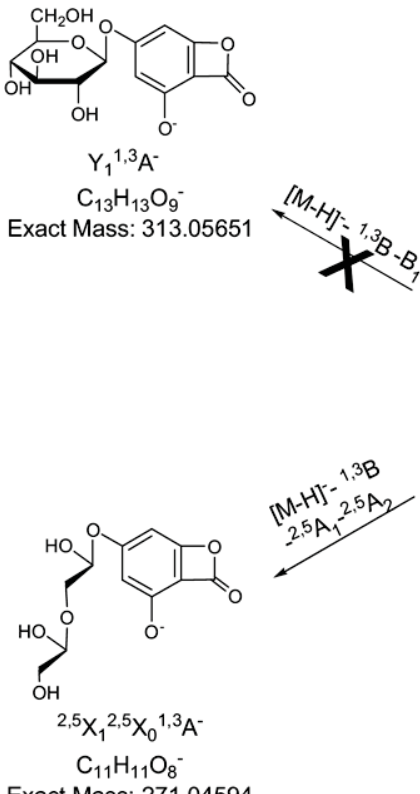

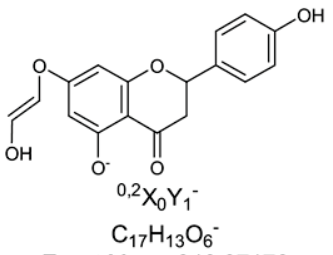

Exact Mass: 313.07176

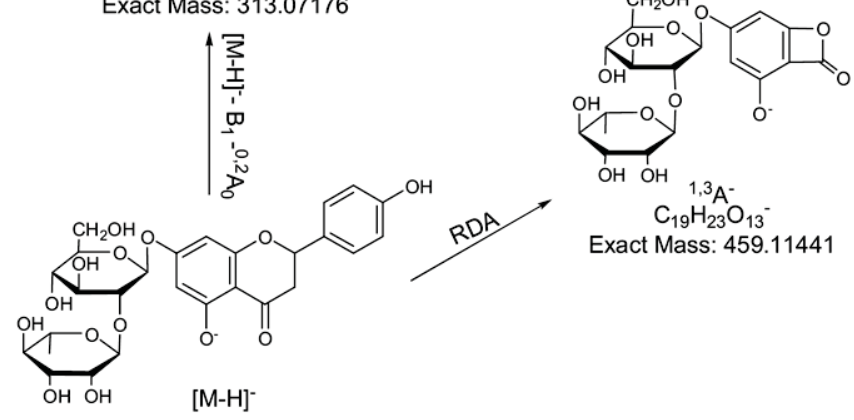

naringin

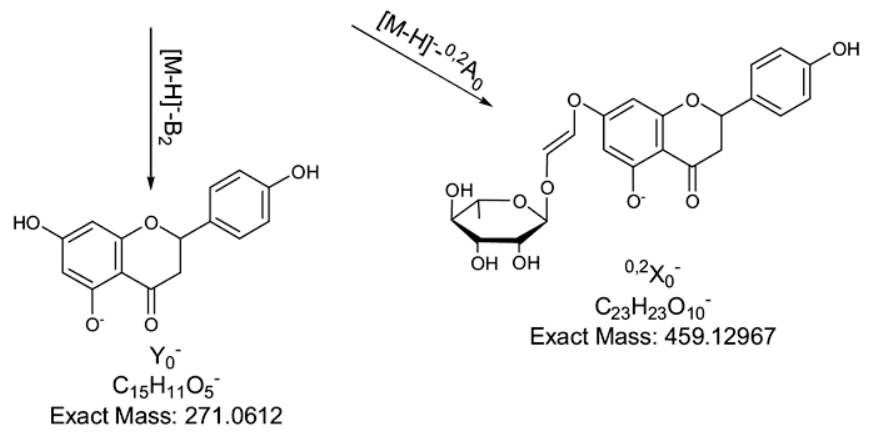

Scheme 3. Fragments of high-resolution SORI CID multibond cleavages from deprotonated naringin and their fragmentation pathways.

energy with new bond formation will compensate for the cross-ring cleavages. Liu et al. also showed this point of view on the structure analysis of saponins [25]. Charge remote process may provide a reasonable explanation for the multibond cleavages that occurred in MS/MS, the deprotonation position on the $5-\mathrm{OH}$ that led to the cross-ring cleavage of the sugar part on the flavonoids. Many peaks of a1, b1, $\mathrm{c} 1$, and $\mathrm{d} 1$ are attributed to multibond cleavage processes. Usually these peaks have lower relative intensity (most of them less than $5 \%$ ) because multibond cleavages need far more energy compared with the monobond or the dibond cleavage processes.

Another noteworthy fact is the $\mathrm{H}_{2}$ loss process from the precursor ions such as $\left.{ }^{0,2} \mathrm{X}_{0} \mathrm{Z}_{1}-\mathrm{H}_{2}\right]^{-}$, $\left[{ }^{0,3} \mathrm{X}_{0} \mathrm{Z}_{1}-\mathrm{H}_{2}\right]^{-},\left[\mathrm{Z}_{1}-\mathrm{H}_{2}\right]^{-}$(see Table 2), and $\left[^{2,4} \mathrm{X}_{1}{ }^{0,2} \mathrm{X}_{0^{-}}\right.$ $\left.\mathrm{H}_{2}\right]^{-}$(see Tables 2 and 3). Losing $\mathrm{H}_{2}$ from C-ring will form a unit conjugate system when the aglycone is flavanone. The fragmentation data of naringin and neohesperidin can provide evidence on the conjugated A-, B-, and C-ring formation. However, there are no fragments related to $\mathrm{H}_{2}$ loss and C-ring cleavages from rhoifolin and neodiosmin, because the flavone aglycone will form an integrated rigid conjugated plane via multi- $\pi$ electrons. So the fragmentation decreased sharply. Although the neohesperidin and neodiosmin possess $4^{\prime}-\mathrm{OCH}_{3}$, the product ion $\left[\mathrm{Y}_{0^{-}} \cdot \mathrm{CH}_{3}\right]^{-}$is only found in the spectra of neodiosmin as shown in Table 5; the odd electron system can be stabilized according to the conjugate system of flavone aglycone.

\section{Conclusions}

FTICR MS SORI CID technique has been proven to be unmatchable in the study of fragmentation pathways of diglycosyl flavonoids. It provided a similar differentiation function on the diglycosyl flavonoids isomers as the ESI-ITMS did, because both possess the low-energy CID characteristics. However, the unambiguous elemental composition deduced from the high mass accuracy measurement can provide the precise fragmentation pathway information. These precise product ions give further detailed information on the charge site location of a precursor ion after collisional activation. Precise bond cleavage positions were assigned based on the reasonable fragmentation pathway. The theoretical calculation modeling results reveal the different configuration between $\alpha 1 \rightarrow 2$ and $\alpha 1 \rightarrow 6$ type flavonoids, which support the fragmentation behavior of these kinds of compounds in ESI FTICR mass spectra. 


\section{Acknowledgments}

The authors acknowledge the financial support of the National Natural Science Foundation of China (30472134) and the Great Research Project of Chinese Academy of Sciences (KGCX2-SW213-06).

\section{References}

1. Gauthier, J. W.; Trautman, T. R.; Jacobson, D. B. Sustained OffResonance Irradiation for Collision-Activated Dissociation Involving Fourier-Transform Mass-Spectrometry: Collision-Activated Dissociation Technique That Emulates Infrared Multiphoton Dissociation. Anal. Chim. Acta 1991, 246, 211-225.

2. Senko, M. W.; Speir, J. P.; McLafferty, F. W. Collisional Activation of Large Multiply Charged Ions Using Fourier Transform Mass Spectrometry. Anal. Chem. 1994, 66, 2801-2808.

3. Iwashina, T. The Structure and Distribution of the Flavonoids in Plants. J. Plant Res. 2000, 113, 287-299.

4. Ma, Y. F.; Shang, F. D. Distribution of Flavonoid in Medicinal Plants. J. Biol. 2003, 20, 35-39.

5. Di Carlo, G.; Mascolo, N.; Izzo, A. A.; Capasso, F. Flavonoids: Old and New Aspects of a Class of Natural Therapeutic Drugs. Life Sci. 1999, 65, 337-353.

6. Pietta, P. G. Flavonoids as Antioxidants. J. Nat. Prod. 2000, 63, 10351042.

7. Nijveldt, R. J.; van Nood, E.; van Hoorn, D. E.; Boelens, P. G.; van Norren, K.; van Leeuwen, P. A. Flavonoids: A Review of Probable Mechanisms of Action and Potential Applications. Am. J. Clin. Nutr. 2001, 74, 418-425.

8. Cos, P.; Ying, L.; Calomme, M.; Hu, J. P.; Cimanga, K.; Van Poel, B.; Pieters, L.; Vlietinck, A. J.; Vanden Berghe, D. Structure-Activity Relationship and Classification of Flavonoids as Inhibitors of Xanthine Oxidase and Superoxide Scavengers. J. Nat. Prod. 1998, 61, 71-76.

9. Sadik, C. D.; Sies, H.; Schewe, T. Inhibition of 15-Lipoxygenases by Flavonoids: Structure-Activity Relations and Mode of Action. Biochem. Pharmacol. 2003, 65, 773-781.

10. Ablajan, K.; Abliz, Z.; Shang, X. Y.; He, J. M.; Zhang, R. P.; Shi, J. G. Structural Characterization of Flavonol 3,7-di-O-Glycosides and Determination of the Glycosylation Position by Using Negative Ion Electrospray Ionization Tandem Mass Spectrometry. J. Mass Spectrom. 2006, 41, 352-360.

11. Cuyckens, F.; Rozenberg, R.; de Hoffmann, E.; Claeys, M. Structure Characterization of Flavonoid O-Diglycosides by Positive and Negative Nanoelectrospray Ionization Ion Trap Mass Spectrometry. J. Mass Spectrom. 2001, 36, 1203-1210.

12. Ferreres, F.; Llorach, R.; Gil-Izquierdo, A. Characterization of the Interglycosidic Linkage in Di-, Tri-, Tetra- and Pentaglycosylated Flavonoids and Differentiation of Positional Isomers by Liquid Chromatography/Electrospray Ionization Tandem Mass Spectrometry. J. Mass Spectrom. 2004, 39, 312-321.
13. March, R. E.; Miao, X. S.; Metcalfe, C. D. A Fragmentation Study of a Flavone Triglycoside, Kaempferol-3-O-Robinoside-7-O-Rhamnoside. Rapid Commun. Mass Spectrom. 2004, 18, 931-934.

14. Prasain, J. K.; Wang, C. C.; Barnes, S. Mass Spectrometric Methods for the Determination of Flavonoids in Biological Samples. Free Rad. Biol. Med. 2004, 37, 1324-1350.

15. March, R. E.; Lewars, E. G.; Stadey, C. J.; Miao, X. S.; Zhao, X.; Metcalfe, C. D. A Comparison of Flavonoid Glycosides by Electrospray Tandem Mass Spectrometry. Int. J. Mass Spectrom. 2006, 248, 61-85.

16. Wu, W.; Yan, C.; Li, L.; Liu, Z.; Liu, S. Studies on the Flavones Using Liquid Chromatography-Electrospray Ionization Tandem Mass Spectrometry. J. Chromatoor. A 2004, 1047, 213-220.

17. Frisch, M. J.; Trucks, G. W.; Schlegel, H. B.; Scuseria, G. E.; Robb, M. A.; Cheeseman, J. R.; Montgomery, J. A., Jr.; Vreven, T.; Kudin, K. N.; Burant, J. C.; Millam, J. M.; Iyengar, S. S.; Tomasi, J.; Barone, V. Mennucci, B.; Cossi, M.; Scalmani, G.; Rega, N.; Petersson, G. A.; Nakatsuji, H.; Hada, M.; Ehara, M.; Toyota, K.; Fukuda, R.; Hasegawa, J.; Ishida, M.; Nakajima, T.; Honda, Y.; Kitao, O.; Nakai, H.; Klene, M.; Li, X.; Knox, J. E.; Hratchian, H. P.; Cross, J. B.; Adamo, C.; Jaramillo, J.; Gomperts, R.; Stratmann, R. E.; Yazyev, O.; Austin, A. J.; Cammi, R.; Pomelli, C.; Ochterski, J. W.; Ayala, P. Y.; Morokuma, K.; Voth, G. A. Salvador, P.; Dannenberg, J. J.; Zakrzewski, V. G.; Dapprich, S.; Daniels, A. D.; Strain, M. C.; Farkas, O.; Malick, D. K.; Rabuck, A. D.; Raghavachari, K.; Foresman, J. B.; Ortiz, J. V.; Cui, Q.; Baboul, A. G.; Clifford, S.; Cioslowski, J.; Stefanov, B. B.; Liu, G; Liashenko, A.; Piskorz, P.; Komaromi, I.; Martin, R. L.; Fox, D. J.; Keith, T.; Al-Laham, M. A.; Peng, C. Y.; Nanayakkara, A.; Challacombe, M.; Gill, P. M. W.; Johnson, B.; Chen, W.; Wong, M. W.; Gonzalez, C.; Pople, J. A. Gaussian 03, Gaussian, Inc.: Pittsburgh, PA, 2003.

18. Ma, Y. L.; Li, Q. M.; van den Heuvel, H.; Claeys, M. Characterization of Flavone and Flavonol Aglycones by Collision-Induced Dissociation Tandem Mass Spectrometry. Rapid Commun. Mass Spectrom. 1997, 11 1357-1364.

19. Domon, B.; Costello, C. E. A Systematic Nomenclature for Carbohydrate Fragmentations in FAB-MS/MS Spectra of Glycoconjugates. Glycoconj. J. 1988, 5, 397-409.

20. Dongre, A. R. Jones, J. L. Somogyi, A. Wysocki, V. H. Influence of Peptide Composition, Gas-Phase Basicity, and Chemical Modification on Fragmentation Efficiency: Evidence for the Mobile Proton Model J. Am. Chem. Soc. 1996, 118, 8365-8374.

21. Chen, G. D.; Pramanik, B. N.; Bartner, P. L.; Saksena, A. K.; Gross, M. L. Multiple-Stage Mass Spectrometric Analysis of Complex Oligosaccharide Antibiotics (Everninomicins) in a Quadrupole Ion Trap. J. Am. Soc. Mass Spectrom. 2002, 13, 1313-1321.

22. Zhang, J.; Brodbelt, J. S.; Wang, J. Threshold Dissociation and Molecular Modeling of Transition Metal Complexes of Flavonoids. J. Am. Soc. Mass Spectrom. 2005, 16, 139-151.

23. Zhang, J.; Brodbelt, J. S. Gas-Phase Hydrogen/Deuterium Exchange and Conformations of Deprotonated Flavonoids and Gas-Phase Acidities of Flavonoids. J. Am. Chem. Soc. 2004, 126, 5906-5919.

24. Es-Safi, N.; Kerhoas, L.; Einhorn, J.; Ducrot, P. Application of ESI/MS CID/MS and Tandem MS/MS to the Fragmentation Study of Eriodictyol 7-O-Glucosyl-( $1 \rightarrow 2)$-Glucoside and Luteolin 7-O-Glucosyl- $(1 \rightarrow 2)$ Glucoside. Int. J. Mass Spectrom. 2005, 247, 93-100.

25. Liu, S.; Cui, M.; Liu, Z.; Song, F.; Mo, W. Structural Analysis of Saponins from Medicinal Herbs Using Electrospray Ionization Tandem Mass Spectrometry. J. Am. Soc. Mass Spectrom. 2004, 15, 133-41. 